\title{
Bullous impetigo
}

INSERM

\section{Source}

INSERM. (1999). Orphanet: an online rare disease and orphan drug data base. Bullous impetigo. ORPHA:36237

Bullous impetigo is a contagious superficial infection occurring in intact skin. Prevalence in the general population is unknown. The disease is characterized by fragile vesicles and flaccid blisters, most often presenting as erosive lesions covered by a yellow crust. The face, trunk and extremities of children under 5 years of age (particularly neonates) are mainly affected. The disease is generally caused by group II Staphylococcus aureus. 